\title{
Social Groups and Economic Inequality
}

\author{
Christopher B. Barrett and Joan Esteban*
}

\author{
April 2005 \\ Guest Editors' Introduction To A Special Issue of the \\ Journal of Economic Inequality
}

\footnotetext{
* We thank Jacques Silber for his support and encouragement of this special issue, Antonio Cabrales, Roberta Dessi, Gösta Esping-Andersen, Marcel Fafchamps, Karla Hoff, Rachel Kranton, Eliana LaFerrara, Jean-Philippe Platteau, Debraj Ray and Fernando Vega for helpful comments on earlier drafts of the papers, Andrea Besley, Angela Hernandez and Cheryl Mrozowski for their excellent work in organizing the February 2004 conference, hosted by the Bank of Spain and the Institut d'Analisi Economica of the Universitat Autonoma de Barcelona, at which these papers were first presented, and The Pew Charitable Trusts and the University of Notre Dame for financial support for the project of which the Barcelona conference was a part.
} 
The five papers that comprise this special issue of the Journal of Economic Inequality are the second in a sequence of collections of papers by a team of economists working on the social and moral dimensions of micro-economic behavior in low-income communities. ${ }^{1}$ These papers share a concern that economically relevant individual characteristics such as inherited wealth, individual skills - whether natural or acquired - or time and effort contributed to work do not adequately explain the distribution of observed incomes, even after allowing for individual random shocks due to "luck". Rather, other individual markers that have no innate significance for economic performance - such as ethnicity, religion, gender, skin color or language - but that identify the social group(s) to which one belongs seem to have considerable power in explaining variation in outcomes such as income, even after controlling for economically relevant characteristics. Indeed, in many if not most societies, one's chances in life may critically depend on group ascription, over and above one's chosen behaviors and initial endowments. It remains a puzzle why intrinsically irrelevant socio-cultural characteristics matter so much to individual and collective performance.

Economic analysis of these crucial social dimensions to economic phenomena can follow any of several promising lines of enquiry. First, given the frequency with which one observes clear socio-cultural differentiation and its apparent salience to individual behaviors, group segmentation must be an equilibrium phenomenon. Given a particular segmentation, it must be that every individual's best action is to cooperate mostly with her own group. This perceived advantage of interacting mostly within one's own group

\footnotetext{
${ }^{1}$ The first set appears in Barrett (2005).
} 
has been termed "social capital". Yet, the idea that it could be desirable to restrict one's set of prospective interactions counters the economist's standard intuition favoring less restricted choice sets. This raises the natural question: what benefits flow from restricting one's interactions to fellow group members and, equivalently, from excluding other social groups?

Second, social cleavages seem far deeper than mere casual introspection suggests. Individuals often appear to decide the tone of their interaction with others on the basis of expectations formed over broad social categories rather than on an individualized basis. Such behaviors lead not only to discrimination but also to conflict. It seems essential to understand the forces driving the process of social categorization that extends prejudices, if not stigma, to broad social groups, with potentially significant economic consequences.

Finally, we need a better understanding of how socially targeted redistributive policies really work. If individual socio-cultural markers are correlated with economic outcomes, it may appear desirable to use information on immutable individual characteristics for targeting purposes. Yet the knowledge that a particular pro-active policy might be enacted can induce choices that end up exacerbating rather than narrowing the differences between the distinct social groups, undermining the intended effects of the policy.

Each of the papers in this special issue advance our understanding of one or more of these key issues at the interplay between social differentiation and economic 
inequality. In their paper, Mogues and Carter explore why economic inequality might be more persistent when it is socially embedded. Socially embedded inequality occurs when income and wealth differences are closely coupled with ethnic, linguistic, racial, religious or any other social trait that creates natural affinities among individuals sharing a common socio-cultural characteristic. Their paper shows how individual identity conditions one's choice of the relationships in which one invests, which in turn affect access to capital and thus wealth accumulation patterns. The core point is that even leaving aside the possibility of discrimination against particular social groups, patterns of endogenous social capital formation may aggravate rather than bridge existing socio-economic cleavages. Where social relationships afford individuals access to economic resources, exogenously given socio-cultural attributes can constrain underprivileged individuals' ability to accumulate capital. Socio-economic polarization can undermine the incentives and ability of the poor to invest in building relationships with wealthier members of other social groups. The result is consistently low economic achievement, not because of overt discrimination or conflict, but rather due to more subtle inter-group variation in the nature of and returns to social interactions.

Intra-group cohesion of the sort so commonly celebrated in the literature on social capital is often inextricable from alienation from other groups. Although individuals commonly exhibit a preference for interacting with others very similar to oneself, this does not automatically imply distaste for, much less hostility towards, individuals alien to one's own social group(s). Nevertheless, significant social cleavages exist and open 
conflict erupts with some regularity even though few people possess innately aggressive preferences towards others.

The paper by Basu explores one plausible explanation for the sharpness of the social cleavages in contrast with the rich variety of individual feelings vis-à-vis the members of the opponent group. In Basu's paper, individuals interact through pair-wise relationships and can opt between cooperation and defection. All may have a preference for interacting with members of the own group so that the pay-offs from interaction across groups are lower than within one's own group. Most of the individuals would nevertheless chose to cooperate with a member of the opposite group. However, the presence of a small minority of radicals who would never cooperate with members outside their own group makes opponents expect defection with probability greater than zero, thus lowering the ex-ante pay-off from cooperation. As a result, marginal individuals will themselves choose not to cooperate, thus increasing even further the probability of encountering a non-cooperator. The sole resulting equilibrium is that nobody cooperates with members of the opposite group. Simply because people have incomplete information about those with whom they might interact and therefore use social markers of no innate importance to form expectations of others' behavior, innocuous differences can lead to social tension and political conflict.

The argument that "statistical discrimination" can create social cleavages is by now well known. Basu's point is that this discrimination can induce behavior that reinforces and radicalizes discrimination. Further, depending on the distribution of 
prejudices over the population, this process may fully unravel and precipitate complete discrimination across the two social groups. A key implications of his argument is therefore that non-discrimination is a fragile equilibrium. It suffices that a small fraction of the population radicalizes its attitude for non-discriminatory cooperation to collapse.

Most of the previous arguments hinge upon the plausible assumption that interactions within one's own group yield a higher pay-off than do interactions across groups. However, the empirical evidence on the gains from social capital and social networking is far from clear. There are some empirical studies on the role of groups, networks and social capital in some communities in developing countries (Grootaert 1999, Narayan and Pritchett 1999, Dasgupta and Serageldin 2000, Fafchamps and Minten 2002, Durlauf and Fafchamps forthcoming), but very little about developed economies. Further, "social capital" has revealed to be a pretty evasive concept, hard to specify, let alone measure.

The contribution of Postlewaite and Silverman is noteworthy in this respect. They examine the impact of one's voluntary participation decisions in social activities early in life on adult wages. In particular, they find that participation in sports activities during one's teen years is a major source of network contacts and of skills valued in the labor market. Those who opt not to participate in such activities suffer social isolation that has a permanent adverse effect on adult wages. This effect naturally leads one to wonder why individuals would choose not to participate in activities known to yield significant long-term rewards. Differences in social treatment due to payoff-irrelevant attributes 
such as ethnicity, gender, race, religion, etc. can lead to differences in participation decisions. Uneven voluntary participation in the social institutions that underpin society can then have long-term consequences for economic inequality, reinforcing pre-existing biases in social treatment.

Because social markers are well-known to play a key role in determining the opportunities open to an individual, a range of targeted redistributional policies have been enacted in various countries in order to counteract spontaneous discrimination, for instance, against women or ethnic or racial minorities. Two of the papers in this special issue address the issue of targeted redistributional policies. Both share a concern about the central role of identity, whether exogenously given by visible markers or the endogenous product of past choices and socioeconomic performance, and about the bifurcation of opportunities and outcomes that can result from processes of social exclusion and alienation that result in equilibrium.

Fryer and Loury focus on affirmative action policies in pair-wise, tournament-like hiring processes. Affirmative action consists of the setting of a diversity target in hiring, when the employer's socially myopic objective is to hire the candidate with the highest level of education or effort. Affirmative action policies can be pursued using information on group identity or not. Knowing the kind of affirmative action policy followed, individuals choose the amount of education in which to invest, determining their competitiveness for available positions. Fryer and Loury show that group-blind affirmative action has strong disincentive effects on the disadvantaged group, resulting 
in a unique semi-separating equilibrium in which a large share chooses zero educational investment, and the size of this cohort increases the more aggressive the affirmative action mandate. Affirmative action policies that do not permit employers to make use of social group information are thus inefficient and lead to socially undesirable patterns of individual investment.

The contribution by Dasgupta and Kanbur explores the effects of group membership on voluntary provision of and access to local public goods and the effects on the optimal targeting of transfers to combat poverty. They note that where groups are communities, then differential access to community-specific public goods constitutes a source of inequality among poor individuals belonging to different groups, an inequality not captured in monetary measures of expenditures or income. These groupdifferentiated patterns of access to public goods have important consequences for the targeting of transfers for poverty reduction. Paradoxically, efficient anti-poverty policies may require tilting transfers in favor of the poor members of richer social groups.

This set of papers underscores how economists can both learn from and contribute to the literature on social groups and their consequences for economic phenomena. We hope that this issue of the Journal of Economic Inequality will attract further attention to the interplay between shared identities associated with socio-cultural markers having no innate significance, and economic interactions that nonetheless rely on such markers and groupings. The predictable consequence is outcomes conditioned by social group 
ascription, and thus economic inequality that clearly transcends a narrowly framed economics perspective.

\section{References}

Barrett, C.B., ed. (2005), The Social Economics of Poverty: Identities, Groups, Communities and Networks. London: Routledge.

Dasgupta, P. and I. Serageldin, eds. (2000), Social Capital: A Multifaceted Perspective. Washington: World Bank.

Durlauf, S. and M. Fafchamps (forthcoming), "Social Capital”, in P. Aghion and S. Durlauf, eds., Handbook of Economic Growth. Amsterdam: North Holland.

Fafchamps, M. and B. Minten (2002), “Returns to Social Network Capital Among Traders," Oxford Economic Papers 54(1): 173-206.

Grootaert, C. (1999), “Social Capital, Household Welfare, and Poverty in Indonesia," Policy Research Working Paper no. 2148, Social Development Department, World Bank.

Narayan, D. and L. Pritchett (1999), “Cents and Sociability: Household Income and Social Capital in Rural Tanzania," Economic Development and Cultural Change 47(4): 871-97. 